\title{
Genetic Epidemiology of the Susceptibility to Leprosy
}

\author{
Edward D. Shields," Douglas A. Russell," and Margaret A. Pericak-Vance \\ *Department of Craniofacial Genetics, Faculty of Dentistry and Center of Human Genetics, McGill University, \\ Montreal H3A-2B2, Quebec, Canada; ${ }^{\ddagger}$ Queensland State Health Service, Brisbane, Australia 4069; and ${ }^{8}$ Division of Neurology, \\ Department of Medicine, Duke University Medical Center, Durham, North Carolina 27710
}

\begin{abstract}
To test the hypothesis that genetic factors are operative in the predisposition to leprosy (Hansen's disease) in humans, a genetic epidemiologic investigation was performed on 269 leprosy kindreds containing 552 affected individuals from an isolated population in Papua New Guinea. The community, and not the family, was the basic social unit. Leprosy, an infectious disease, was not communal but strongly familial within the Karimui. Segregation analysis, to determine whether a major gene for the susceptibility to leprosy was segregating within a single multigenerational kindred, could not differentiate between a Mendelian genetic and a purely environmental hypothesis. The composite kindred data, however, suggest a genetic hypothesis for the nonimmunologically induced susceptibility to leprosy per se. Within familial kindreds leprosy invariably emanated from a common ancestral sibship, and risk was associated with the closeness of kin but not with infectivity or severity.
\end{abstract}

\section{Introduction}

Leprosy (Hansen's disease), which affects about 15 million people worldwide, is an infectious disease caused by the Mycobacterium leprae (M. leprae). Clinically, leprosy is manifested as a disease spectrum with two polar forms, lepromatous-LL and tuberculoid-TT. The spectrum is further divided into infectious multibacillary forms, LL, BL, LI; paucibacillary forms, TT, BT, BT/TT, IND; and a transitional borderline form, BB. Affected individuals within the paucibacillary group may spontaneously recover $(1,2)$. Indeterminate (IND) leprosy is unique, because it is not only transitional to all other leprosy types but it is also the most frequent type to heal spontaneously (1).

Once an individual develops leprosy, it is manifested as a leprosy type on the clinical spectrum. Although the spectrum appears to be directly related to the continuous activity of cell-

An abstract of this paper was presented at the 11 th International Leprosy Congress, New Delhi, India, 1984. This study was approved by a Medical Research Council of Canada Ethical Review Committee and informed consent, as deemed reasonable by the Committee for such primitive conditions, was obtained. Dr. Russell is a consultant on Hansen's disease to the Queensland State Health Service, Australia and to the Southeast Asia Leprosy Mission (United Kingdom).

Address reprint requests to Dr. Shields, Department of Craniofacial Genetics, Faculty of Dentistry and Center of Human Genetics, McGill University, 3640 University Street, Montreal H3A 2B2, Quebec, Canada. 1986.

Received for publication 27 May 1986 and in revised form 13 October

J. Clin. Invest.

c) The American Society for Clinical Investigation, Inc.

$0021-9738 / 87 / 04 / 1139 / 05 \$ 1.00$

Volume 79, April 1987, 1139-1143 mediated immunity $(3,4)$, the precise definition of an affected individual remains vague.

Multibacillary infectious cases (and potentially reactional TT and BT) $(5,6)$, may be infective long before they are diagnosed. Multibacillary individuals present three paradoxical findings: $(a)$ they do not appear to transmit multibacillary forms to their close contacts at any greater rate than do other forms $(7,8)$, although they obviously present a much heavier exposure of $M$. leprae; $(b)$ they do not tend to cluster in multiplex kindreds (greater than one affected in the kindred) (9); (c) the secondary attack rate is small (9).

Most individuals in an endemic area $(7,10)$ and many in areas of low leprosy prevalence (11) have been infected with $M$. leprae, yet few actually contract leprosy $(12,13)$. As emphasized by Spickett (14), prevalence in an endemic area is independent of contact with a multibacillary case.

De Vries et al. (15-17), using family data from both South America and India, hypothesized that major histocompatibility loci in humans (HLA) may function in the host response to $M$. leprae. Several associations between polar leprosy types and specific HLA alleles have been identified in various populations (18-20). Loose genetic linkage between an HLA locus and an autosomal recessive susceptibility to tuberculoid leprosy has been suggested from a study of an Indian population (21).

The genetic implications of the host's ability to respond to mycobacterial invasion have also been repeatedly identified in animal models (22-24). The genetics of the natural or nonimmunologic resistance to intracellular parasites is frequently described as complex although single genes with major effects have been dissected out (25). In inbred mice natural resistance to intracellular parasites is typified by its variability. Even within a single strain that is considered to be susceptible, a large amount of variability is demonstrated (26).

Skamene et al. (27) have shown that the susceptibility and resistance to other mycobacterial infections and intracellular parasites in inbred mice is controlled by a single, non-major histocompatibility complex (MHC)-linked, autosomal locus. However, if the experimental bacterial dose is large enough, even a genetically resistant animal will succumb (28).

The objective of our investigation was to test the hypothesis that genetic factors are operable in the predisposition to leprosy per se. The study population (an isolate from the Highlands of Papua New Guinea) was chosen because it was believed that such a unique human population would mitigate many problems in a search for genetic factors in the pathogenesis of a disease caused by an environmental agent. Under the assumption of an underlying susceptibility to leprosy, a thorough examination of the familial kindreds was performed. The following was observed within these kindreds: $(a)$ leprosy appeared in multiple generations and in $92 \%$ of the cases, direct descent from a common ancestral sibship (vertical transmission); (b) affected conjugal pairs had high risk of having affected offspring only if both came from affected kindreds; $(c)$ half siblings had equal risks; $(d)$ al- 
though affected mothers represented the main potential source of infection, affected mothers did not have a greater risk of producing affected offspring than affected fathers; and $(e)$ there were numerous instances where both father and son were affected.

\section{Methods}

An isolated, unacculturated, swidden agriculturist Papua New Guinea population, the Karimui, was chosen for this study because of the following unique population characteristics:

Total ascertainment over a 19 yr period. Annual leprosy patrols have been performed in the Karimui since 1962 excluding 1963 and 1965. Each patrol consisted of a thorough examination of every resident for evidence of leprosy lesions.

Uniform ascertainment. All examinations were done by one examiner (Dr. Russell).

Confirmatory diagnosis. All suspect lesions were biopsied and microbiologic smears were taken. The biopsy specimens were sent to one histopathologist (Dr. D. S. Ridley, London), and the skin slit smears bacteriology studies were sent to one microbiologist (Dr. C. Shepard, Atlanta, GA).

$A$ unique social order produced a nearly uniform contact to $M$. Leprae by the entire population (29). The Karimui region is located on the southern slopes of the central New Guinea Highlands. The Karimui is an isolated, endemic leprosy population which does not live in family units but rather in dynamic communal units; for example, husbands and wives do not cohabitate (30). The mother is the major contact individual for infants and children during the critical time of infection (29). Food and other social economic parameters are uniformly distributed throughout this society.

Polygyny is common. Many half siblings are available for analysis.

The Karimui kindreds were examined in the following manner: each resident was examined for leprosy lesions and their place within a nuclear family was defined. Nuclear families were assessed and large kindreds were constructed through direct interrogation of all residents (by Dr. Shields and Nara of Sogo-1). The data were coded and transformed into a SAS (31) computer data set.

In subsequent patrols pregnancy outcomes were noted and the kindred data were verified both by reinterrogation of the same individuals and through the interview of kindred members residing in outlying villages. Discrepancies in the data were corrected with the aid of village leaders and local genealogists. The process of constructing large, multigenerational kindreds from the nuclear families occurred during four annual leprosy patrols.

Accurate genealogical information is very important to the stability of the Karimui society. This accuracy is typified by the central cultural role of inbreeding taboos, bride selection and price, and "pagabidi" fees (a fee paid for each child by the father to the mother's brothers) (30).

Because of the variable age of onset of leprosy, 1972 was chosen as the last birth year for all analyses. Two advantages of this early cutoff are the mollification of the treatment effect, which began in 1968, and of Western influence which has recently started to emanate from the Karimui airstrip.

Segregation analysis was performed on a single multigenerational kindred composed of 89 individuals, 19 of which were affected. The analysis was done according to the methods of Elston and co-workers (32-34). The following hypotheses were tested: $(a)$ the simple Mendelian hypothesis and $(b)$ an environmental hypothesis assuming no transmission between generations. All hypotheses were tested by the likelihood ratio criterion.

\section{Results}

The original sample consisted of 269 leprosy kindreds and 552 probands (prevalence in $1962=301$ of $5,063=6 \%$ [35]). Of these kindreds 31 had first, second, or both degree relatives af- fected by history (for example, a dead parent) and thus could not be classified as to their familial nature. These kindreds were deleted from the analysis leaving 238 leprosy kindreds. The following analyses were done on individuals examined since 1963 and thus, under total ascertainment.

A count of the probands in each pedigree identified an apparent dichotomy in the distribution of affected individuals. $22 \%$ (52 of 238) of the pedigrees contained 58\% (301 of 521) of the affected individuals. The pedigrees were thus divided into two groups: familial (greater than one proband in the first two-degree relatives) and nonfamilial (one proband in the first two-degree relatives). Within the familial group leprosy was frequently observed to pass vertically through multiple generations (79 of 89 $=89 \%$ ). $92 \%$ ( 343 of 372 ) of the affected individuals from familial kindreds had direct descent of leprosy from a single ancestral affected sibship. Frequently a generation was skipped. Only $11 \%$ of the familial kindreds were horizontally affected.

Of the 29 affected individuals from high at risk sibships (offspring of parents both of which were either affected, from highrisk kindreds or both), nine had parents both of which were from highly familial (multiplex) kindreds. The risk in the sibships of these nine affected individuals was an extraordinary $64 \%$ (9 of 14-Table I). The following was observed among the three spouse pairs that produced these extraordinary high-risk sibships: in one pair neither was affected, the second pair had a husband with TT leprosy, and one pair was conjugally affected. The risk among the remaining 20 affected individuals who had bilateral risk decreased directly $(52 \%, 32 \%)$ with their parental risk.

Although most of the first $10 \mathrm{yr}$ of life are spent with the mother, affected Karimui mothers did not have a greater risk of having offspring with leprosy (33 of $18818 \%$ ) than did affected fathers $\left(37\right.$ of $\left.165,22 \%-\chi^{2}=1.31\right)$. Of the 24 conjugal affected parents, $18.6 \%$ ( 8 of 43 ) of their offspring ( $>10 \mathrm{yr}$ old) were affected and all eight of the affected offspring (8 of $11,73 \%$ ) came from two familial (and multibacillary) kindreds. Five of the six affected parents in the above two kindreds (two conjugal pairs were observed in the same kindred) had near ascendants

Table I. Leprosy Risk Decreased Directly with Parental Genetic Risk in Familial Kindreds

\begin{tabular}{lcccc}
\hline & \multicolumn{2}{l}{ Offspring $(n)$} & & \\
\cline { 2 - 4 } & Affected & Normal & Total & $\begin{array}{l}\text { Percent } \\
\text { affected }\end{array}$ \\
\hline $\begin{array}{l}\text { Kindrents } \\
\quad \text { proband or not) }\end{array}$ & & & & \\
$\quad \begin{array}{l}\text { Very high risk* } \\
\text { High risk }\end{array}$ & 9 & 5 & 14 & 64 \\
$\quad$ Moderate risk & 11 & 10 & 21 & 52 \\
Probands & 9 & 19 & 28 & 32 \\
& 70 & 283 & 353 & 20 \\
\hline
\end{tabular}

$\chi^{2}=3.94 ; P=0.047$ (very high risk vs. moderate risk).

$\chi^{2}=24.89 ; P=0.001$ (very high and moderate risk vs. probands).

* Both parents from highly familial kindreds (one, neither parent affected; one, conjugal affected; one, single spouse affected).

${ }^{\ddagger}$ Both parents either affected or have an affected first-degree relative (one, neither parent affected; two, conjugal affected-same kindred; three, single spouse affected).

One parent affected or from a familial kindred or has an affected half sib, second parent has an affected third-degree relative (six, neither parent affected; one, spouse affected). 
affected, whereas there was insufficient data on the sixth parent. The offspring of this last pair (five affected, none normal) were classified in the "high-risk" category in Table I.

The entire spectrum of leprosy defects were manifest within single familial kindreds. Multibacillary and paucibacillary affected individuals had unequal risks for affected offspring $\left(\chi^{2}\right.$ $=5.74 ; 0.025>P>0.01)$. However, this risk variance disappeared in combined multibacillary and combined paucibacillary cases (Table II), when indeterminate groupings were subtracted $\left(\chi^{2}=2.95\right)$. The risk for multibacillary offspring was evenly distributed between the various leprosy types except for polar lepromatous and indeterminate forms; e.g., risk is for leprosy per se. Within multibacillary kindreds only $7 \%$ (10 of 134) of the affected individuals were multibacillary, which is equal to the proportion of multibacillary cases in the overall leprosy population. To relieve the bias of identifying a multibacillary kindred (kindred with at least one multibacillary member) through a multibacillary individual, index multibacillary cases (the first ascertained multibacillary case in a kindred) were deleted for this calculation.

During the nearly 6-yr period in which data were obtained and treatment was not available, 16\% (63 of 405) of the affected individuals spontaneously healed. A comparison of the proportion of healed cases in familial (38 of 271) vs. nonfamilial kindreds (25 of 134) showed no significant difference $\left(\chi^{2}=1.47\right)$. $94 \%$ (17 of 18) of BB individuals were in familial kindreds and a significant proportion of these $\left(13\right.$ of $\left.20, \chi^{2}=3.95 ; P<0.05\right)$ were in multibacillary kindreds. For these analyses BB was considered as multibacillary. The mean age of onset among the 216 familial and 97 nonfamilial probands who developed leprosy after the first leprosy patrol was 18 and $20 \mathrm{yr}$, respectively. A comparison of a square root transformation of the age of onset between the two groups showed a significant difference between the means $(P=0.036)$. Both familial index cases (15 affected, 99 normal) and their affected half siblings (15 affected, 95 normal) had equal risk for further affected siblings $\left(\chi^{2}=0.01\right.$ for

Table II. Risk in the Offspring of Probands from Familial Kindreds by Parental Leprosy Type

\begin{tabular}{lrrrr}
\hline & \multicolumn{2}{c}{ Offspring } & & \\
\cline { 2 - 4 } Parental leprosy type & Affected & Normal & Total & $\begin{array}{r}\text { Percent } \\
\text { affected }\end{array}$ \\
\hline Multibacillary & & & & \\
LL & 4 & 7 & 11 & 36 \\
BL & 11 & 16 & 27 & 41 \\
BB & 0 & 7 & 7 & 0 \\
Total & 15 & 30 & 45 & 33 \\
Paucibacillary & & & & \\
BT & 21 & 79 & 100 & 21 \\
BT/TT & 5 & 12 & 17 & 22 \\
TT & 20 & 69 & 89 & 22 \\
IND/TT & 0 & 9 & 9 & 0 \\
Total & 46 & 169 & 215 & 21 \\
IND & 9 & 81 & 90 & 10 \\
Grand total & 70 & 280 & 350 & 20 \\
& & & & \\
\hline
\end{tabular}

IND, indeterminate leprosy.

$\chi^{2}=2.95$ (multibacillary vs. paucibacillary - IND deleted) the analysis one affected individual was deleted per sibship). There were 23 cases of affected fathers and sons. Table II indicates that although the clinical spectrum corresponds to the continuous gradation of $\mathrm{T}$ lymphocyte performance (3), if one excludes indeterminate forms, the severity spectrum does not directly correlate with risk.

The segregation analysis of one multigenerational kindred tested each the Mendelian dominant, recessive, and codominant hypotheses against the unrestricted model. None of the genetic hypotheses could be rejected when tested $(P>0.05)$. The environmental null hypothesis was also tested and could not be rejected $(P>0.05)$. In fact, the resulting likelihoods for the various hypotheses were approximately equal.

\section{Discussion}

The finding that within the Karimui, wives had no greater risk than husbands of having affected children, along with corroborating epidemiologic data; e.g., $M$. leprae may remain viable for weeks (36-38) and casual contact is sufficient for sensitization $(39-41)$, and the unique social factors within the study area, suggest that environmental factors are uniformly distributed. Social biological interplay factors such as individual response to stress (42) was not directly controlled for in this study.

The highly uniform environment within the Karimui, associated with the fluidity of the family organization, provides an opportunity to address the question whether a single gene has a major effect on the susceptibility to an infectious disease in humans. The finding of a dichotomous distribution of kindred types (familial and nonfamilial) suggests pathogenic heterogeneity within the Karimui leprosy kindreds. Of the 238 kindreds, 149 (63\%) were nonfamilial, that is, a single affected individual within the pedigree. Purely environmentally induced cases plus chance isolated cases likely compose this nonfamilial group of kindreds. Chance isolated cases are potentially familial cases, which have a single affected individual by chance along or because of the late age of onset in the disease. The familial kindreds appear to have an underlying susceptibility. The remaining Karimui kindreds are leprosy free. ${ }^{1}$

The risk for contracting leprosy per se was relatively unperturbed by either the infectivity or the severity of the disease in the parent. The data from parents, both of whom had a family history of leprosy, corroborated the above finding in affected mothers that the leprosy status of the parent was not the prime determining factor of risk. Risk was determined by whether or not the parent came from a familial kindred. When both parents came from highly familial kindreds, the risk for leprosy in their offspring was $64 \%$ (Table I). This risk was similar to the concordance rate for leprosy in monozygous twins (43). The risk decreased to $52 \%$ and $32 \%$ as the number of leprosy cases in the family decreased and as other affected kindred members were more distant relatives.

Leprosy is an infectious and apparently familial disease. The basic social unit within the Karimui is not the family but the community, and thus the spread of an infectious disease would be expected to be communal and not familial. Within the Karimui the majority of common familial environmental effects

1. Shields, E. D., and D. A. Russell. Leprosy in the Karimui, New Guinea: observations on the inherent individual variation in its susceptibility. Manuscript in preparation. 
can be excluded. The observed familial nature of leprosy in the Karimui regardless of the living situation of that family suggests that genetic susceptibility factors are implicated in the pathogenesis of the disease.

A paradigm may be developed from the above structural findings in which a single megaphenic leprosy susceptibility factor may segregate through a proportion of the Karimui kindreds. This putative factor would predispose the carrier to leprosy per se. That the susceptibility factor predisposes the carrier to leprosy infection and not a specific leprosy type is compatible with the finding of discordance for leprosy type in concordant monozygous twins (43). The twin data are indeed striking because most leprosy is classified as paucibacillary (the twin data remain preliminary owing to its small sample size and the need to fully document zygosity). Our data are also in accord with the observed genetics of nonimmunologically induced resistance-susceptibility to Mycobacterium bovis in inbred mice (44), although the susceptibility allele is Mendelian recessive in the mouse.

The segregation analysis tested the hypothesis that a major gene for the susceptibility to leprosy was segregating in one large multigenerational pedigree. The results of the segregation analysis indicated that there was not enough inforthation available in the pedigree to allow discrimination between the competing hypotheses.

Van Eden et al. (19) emphasized the finding that HLA-linked genes, likely immune response (Ir) or immune suppression (Is) genes, appear to have a rolę in determining where the postinfected individual lies on the clinical disease spectrum. Furthermore, these authors found no evidence that HLA-linked alleles function in the susceptibility to leprosy per se.

The putative susceptibility locus, as hypothesized in this study, would be one gene (not HLA associated or linked) in the multifactorial pathogenesis of leprosy. This susceptibility gene would set the stage for infection allowing HLA haplotypes, further environmental factors or both, to precipitate a specific leprosy type. It must be reemphasized that within the Karimui most sporadic and some familial cases may be purely environmentally induced.

A genetic hypothesis for a role in the pathogenesis of the natural susceptibility to leprosy in a segment of the leprosy population may arguably be considered as a genetic world view. An alternate environmental hypothesis can be invoked for any observed human variation whereas a genetic hypothesis is a natural hypothesis given known genetic factors in the nonimmunologic resistance and susceptibility to intracellular parasites.

\section{Acknowledgments}

The authors wish to express their appreciation to Le Secours Aux Lepreux (Leprosy Relief, Canada), Inc., for its continuing financial and moral support throughout this extended study and also to the Southeast Asia Leprosy Mission (United Kingdom), for their support for the $1979 \mathrm{Kar}-$ imui patrol. Our thanks also go out to the Papua New Guinea Institute of Medical Research in Goroka, for its assistance during the field study and to the University of Papua New Guinea for their grant whith helped initiate this project. The study could not have been completed without Nara, whose efforts in translation and knowledge as a genealogist and as an understanding counsellor are greatly appreciated and also Douglas Tahwaigu of the Papua New Guinea Public Health Department, both for his years of hard work on the Karimui leprosy project and the improvement of the health of the Karimui people. We also are most grateful to Robert C. Elston, Department of Biostatics, Louisiana State University for his statistical advice on the segregation analysis.

\section{References}

1. Scott, G. C., D. A. Russell, C. R. Boughton, and D. R. Vincin. 1976. Untreated leprosy. Probability of shifts in Ridley-Jopling classifcation: development of "flares," or disappearance of clinical apparent disease. Int. J. Lepr. 44:110-122.

2. Stanley, S. J., C. Howland, M. M. Stone, and I. Sutherland. 1981. BCG vaccination against leprosy in Uganda: final results. J. Hyg. 87: 233-248.

3. Myrvang, B., T. Godal, D. S. Ridley, S. S. Froland, and Y. K. Song. 1973. Immune responsiveness to Mycobacterium leprae and other mycobacterial antigens throughout the clinical and histopathologic spectrum of leprosy. Clin. Exp. Immunol. 14:541-553.

4. Sansonetti, P., and P. H. Lagrange. 1981. The immunology of leprosy: speculations on the leprosy spectrum. Rev. Infect. Dis. 3:422469.

5. Wade, H. W., and V. Ledowsky. 1952. The leprosy epidemic at Nauru: a review with data on the status since 1937. Int. J. Lepr. 20:129.

6. Leiker, D. L. 1960. Epidemiological and immunological surveys in Netherlands New Guinea. Lepr. Rev. 31:241-259.

7. Godal, T. 1978. Immunological aspects of leprosy-present status. Prog. Allergy. 25:211-242.

8. Menzel, S., G. Bjune, and G. Kronvall. 1979. Lymphocyte transformation test in health contacts of patients with leprosy. I. Influence of exposure to leprosy within a household. Int. J. Lepr. 47:138-152.

9. Guinto, R. S., J. A. Doull, and E. B. Mabalay. 1955. The Mitsuda reaction in persons with and without household exposure to leprosy. Int. J. Lepr. 23:135-138.

10. Convit, J., M. E. Pinardi, F. A. Rojas, I. Gonzales, G. Corey, J. J. Arvelo, and H. Monzon. 1975. Tests with three antigens in leprosyendemic and non-endemic areas. Bull. WHO. 52:193-198.

11. Abe, M., F. Minagawa, Y. Yoshino, T. Ozawa, K. Saikawa, and T. Saito. 1980. Fluorescence antibody absorption (FLA-ABS) test for detecting subclinical infection with Mycobacterium leprae. Int. J. Lepr. 48:109-119.

12. Godal, T., and K. Negassi. 1973. Subclinical infection in leprosy. Br. Med. J. 13:557-559.

13. Kronvall, G., G. Bjune, J. Stanford, S. Menzel, and D. Samuel. 1975. Mycobacterial antigens in antibody responses of leprosy patients. Int. J. Lepr. 43:299-306.

14. Spickett, S. G. 1962. Genetics and the epidemiology of leprosy. I. The incidence of leprosy. Lepr. Rev. 33:76-93.

15. De Vries, R. R. P., R. F. M. Lai A Fat, and L. E. Nijenhaus. 1976. HLA-linked genetic control of host response to Mycobacterium leprae. Lancet. ii:1328-1330.

16. De Vries, R. R. P., J. J. Van Rood, R. F. M. Lai A Fat, N. K. Mehra, and M. C. Vaidya. 1979. Is susceptibility to tuberculoid leprosy due to a recessive HLA-linked gene? In Immune Mechanisms and Disease. D. B. Amos, R. S. Schwartz, and B. W. Janicki, editors. Academic Press, Inc., New York. 283-299.

17. De Vries, R. R. P., M. K. Mehra, M. C. Vaidya, M. D. Gupte, P. M. Khan, and J. J. Van Rood. 1980. HLA-linked control of susceptibility to tuberculoid leprosy and association with HLA-DR types. Tissue Antigens. 16:89-112.

18. Fine, P. E. M., E. Wolf, J. Pritchard, B. Watson, D. J. Bradley, H. Festenstein, and C. J. G. Chako. 1979. HLA-linked genes and leprosy: a family study in Karigari, South India. J. Infect. Dis. 140:152-160.

19. Van Eden, W., N. M. Gonzalez, R. R. P. De Vries, J. Convit, and J. J. Van Rood. 1985. HLA-linked control of predisposition to lepromatous leprosy. J. Infect. Dis. 151:9-14.

20. Demenais, F., V. Goulet, N. Feingold, J. Millan, M. Blanc, C. Raffoux, and E. Bois. 1985. Genetic study of leprosy in a Caribbean island: Desirade. In Genetic Control of Natural Resistance to Infection and Malignancy. E. Skamene, editor. Alan R. Liss, Inc., New York. 319324.

21. Haile, R. W. C., L. Iselius, P. E. M. Fine, and N. E. Morton. 
1985. Segregation and linkage analysis of 72 leprosy pedigrees. Hum. Hered. 35:43-52.

22. Closs, O., and O. Haugen. 1974. Experimental murine leprosy. II. Further evidence for varying susceptibility of outbred mouse strains to infection with Mycobacterium lepraemurium. Acta Pathol. Microbiol. Scand. 82:459-474.

23. Lurie, M. B. 1964. Resistance to Tuberculosis: Experimental Studies in Native and Acquired Defensive Mechanisms. Harvard University Press, Cambridge, MA. 1-324.

24. Shepard, C. C., and J. A. Habas. 1967. Relation of infection to tissue temperature in mice infected with Mycobacterium marinum and Mycobacterium leprae. J. Bacteriol. 93:790-796.

25. Potter, M., A. D. O'Brien, E. Skamene, P. Gros, A. Forget, P. A. L. Kongshavn, and J. S. Wax. 1983. A BALB/c congenic strain of mice that carries a genetic locus (Ity-r) controlling resistance to intracellular parasites. Infect. Immun. 40:1234-1235.

26. Stevenson, M. M., J. J. Lyanga, and E. Skamene. 1982. Murine malaria: genetic control of resistance to Plasmodium chadbaudi. Infect. Immun. 38:80-88.

27. Skamene, E., P. Gros, A. Forget, P. A. L. Kongshavn, C. St. Charles, and B. A. Taylor. 1982. Genetic regulation of resistance to intracellular pathogens. Nature (Lond.). 297:506-509.

28. Skamene, E., and P. A. L. Kongshavn. 1983. Cellular mechanisms of resistance to Listeria monocytogenes. Adv. Exp. Biol. Med. 162:217225 .

29. Hausfeld, R. G. 1970. An anthropological method for measuring exposure to leprosy in a leprosy-endemic population at Karimui, New Guinea. Bull. WHO. 43:863-877.

30. Wagner, R. 1967. The Curse of Souw. University of Chicago Press, Chicago. 1-279.
31. SAS User's Guide: Basics. 1982. SAS Institute, Inc., Cary, NC. $1-923$.

32. Elston, R. C. 1981. Segregation analysis. Adv. Hum. Genet. 11: 63-120.

33. Elston, R. C., and J. Stewart. 1971. A general model for the genetic analysis of pedigree data. Hum. Hered. 21:523-542.

34. Elston, R. C., and K. C. Yelverton. 1975. General models for segregation analysis. Am. J. Hum. Genet. 27:31-45.

35. Russell, D. A., G. C. Scott, and S. C. Wigley. 1964. BCG vaccination in leprosy. Int. J. Lepr. 32:235-247.

36. Davey, T. F., and R. J. W. Rees. 1974. The nasal discharge in leprosy: clinical and bacteriological aspects. Lepr. Rev. 45:121-134.

37. Desikan, K. V. 1977. Viability of Mycobacterium leprae outside the human body. Lepr. Rev. 48:231-235.

38. Ramu, G. 1981. Central JALMA Institute for leprosy, AgraAnnual report 1979. Lepr. India. 53:307-315.

39. Draper, P. 1976. Cell walls of Mycobacterium leprae. Int. J. Lepr. 44:95-98.

40. Leiker, D. L. 1977. On the mode of transmission of Mycobacterium leprae. Lepr. Rev. 48:9-16.

41. Stanford, J. L., G. A. W. Rook, J. Convit, T. Godal, G. Kronvall, R. J. W. Rees, and G. P. Walsh. 1975. Preliminary taxonomic studies on the leprosy bacillus. Br. J. Exp. Pathol. 56:579-85.

42. Rahe, R. H. 1972. Subjects' recent life changes and their nearfuture illness susceptibility. Adv. Psychosom. Med. 8:2-19.

43. Chakravartii, M. R., and F. Vogel. 1973. A twin study on leprosy. Top. Hum. Genet. 1:1-123.

44. Gros, P., E. Skamene, and A. J. Forget. 1981. Genetic control of natural resistance to Mycobacterium bovis (BCG) in mice. J. Immunol. 127:2417-2421. 